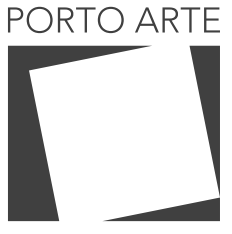

Revista de Artes Visuais

V. $25 \div .43$

\section{Exposição Vaivém (2019-2020), com curadoria de Raphael} Fonseca

To-and-Fro Exhibition (2019-2020), curated by por Raphael Fonseca

\section{Lindomberto Ferreira Alves}

ORCID: 0000-0001-7832-1734

Universidade Federal do Espírito Santo, Brasil.

\section{Resumo}

A resenha perscruta aspectos da exposição Vaivém (2019-2020), de curadoria do historiador da arte Raphael Fonseca, cujo projeto curatorial vem operando, por aproximações e embates, um embalo reflexivo sobre as relações entre as representações iconográficas das redes de dormir e suas finalidades discursivas na constituição das noções de identidade brasileira, do século XVI à contemporaneidade.

Palavras-Chave

Exposição Vaivém. Redes de dormir. Imagem. Raphael Fonseca. Curadoria.

\section{Abstract}

The review examines aspects of the To-and-Fro exhibition (2019-2020), curated by art historian Raphael Fonseca, whose curatorial project has operated, through approximations and clashes, a reflective packaging on the relations between the iconographic representations of the hammocks and their discursive purposes in the constitution of notions of Brazilian identity, from the 16th century to the contemporary.

Keywords

To-and-Fro exhibition. Hammocks. Image. Raphael Fonseca. Curatorship. 


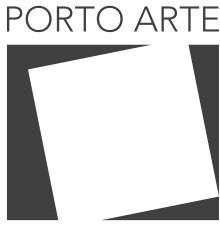

Revista de Artes Visuais

$\vee 25 n .43$

Jan/jun 2020 e-ISSN: 2179-8001

\section{Resumo}

A exposição Vaivém (2019-2020), de curadoria do historiador da arte, crítico e curador Raphael Fonseca, vem operando, por aproximações e embates, um embalo reflexivo sobre as relações entre as representações iconográficas das redes de dormir e suas finalidades discursivas na constituição das noções de identidade brasileira, do século XVI à contemporaneidade. Embora Raphael Fonseca tenha encaminhado o projeto curatorial da exposição Vaivém à chamada pública do Programa Banco do Brasil de Patrocínio 2019/2020, em 2018, as bases do projeto foram urdidas, na verdade, entre os anos de 2012 e 2016, durante a realização de sua pesquisa doutoral1, no âmbito do Instituto de Artes da Universidade Estadual do Rio de Janeiro.

Mesmo que não se tenha tido a chance de deambular as 468 páginas da tese cuja façanha de fôlego nos enreda - fluindo sempre com direção e inteligência, a serviço da construção de um chão conceitual que ampare a complexificação das histórias e das iconografias das redes de dormir, no Brasil - é praticamente impossível percorrer a exposição Vaivém e não se atentar para o grandioso trabalho de investigação e pesquisa que há por detrás dela. Se por ventura isso não se faça evidente no contato imediato com o conjunto de 350 obras que compõem a mostra - que vão do século XVI a obras produzidas exclusivamente para a exposição - o próprio Raphael nos faz saber de diferentes maneiras. E é importante que isso seja dito por uma razão bem simples: dado que quase a totalidade das produções científicas tem sua circulação e discussão circunscritas à própria academia, é no contrafluxo desse movimento que podemos localizar a ação de Raphael Fonseca quando se propõe a empreitada de "transformar"2 a tese Construções do Brasil no vaivém da rede de dormir (2016) no projeto curatorial da exposição Vaivém (2019-2020). Com essa ação, Raphael reforça a urgência em se propor formas de alianças que permitam o amplo acesso à pesquisa realizada nas instituições educacionais públicas no nosso país, e evidencia a importância da pesquisa, no âmbito das instituições culturais, para a promoção de um acesso à cultura e à fruição artística que de fato favoreçam a formação crítica do público e a ampliação do repertório cultural da sociedade.

Assim, a mostra Vaivém - que já passou pelas unidades do Centro Cultural Banco do Brasil de São Paulo/SP, Brasília/DF e Rio de Janeiro/RJ, encerrando sua itine-

\footnotetext{
1- Inquirindo a questão "quais Brasis foram inventados imageticamente a partir dessa apropriação e quais as intenções daqueles que discursaram?", a partir de 950 trabalhos (entre obras de arte e imagens vinculadas à cultura visual, num sentido mais amplo) a tese Construções do Brasil no vaivém da rede de dormir (2016) foi estruturada em três grandes capítulos. O primeiro reuniu imagens produzidas durante a colonização do Brasil (da invasão das Américas até a proclamação da República). O segundo envolveu imagens vinculadas à reconfiguração das redes de dormir no imaginário nacional moderno. E o terceiro apresentou obras produzidas nos últimos trinta anos por artistas brasileiros, aferindo como os artistas de diferentes gerações, desde os anos 1990, têm usado as redes para criar certa imagem da brasilidade, especialmente fora do país, a exemplo de Ernesto Neto, Paula Lima, Alan Queiroz, Tunga, entre outros.

2- Note que o uso das aspas, aqui, não é arbitrário, uma vez que, segundo o próprio curador "[...] o espaço de escrita discursiva curatorial é certamente outro quando comparado com os limites de uma folha de pape e a escrita de uma tese doutoral" (FONSECA, 2016). E, mais recentemente, complementa: "diferente da experiência virtual de escrever uma tese, organizar uma exposição se trata de um grande esforço coletivo em colocar 'coisas', objetos, um ao lado do outro" (FONSECA, 2019a, p. 11), num complexo processo crítico de montagem a partir da justaposição de fragmentos a partir de suas diferenças, tensionando outros modos possíveis de narrar uma determinada memória, pautados no anacronismo e na polifonia.
} 


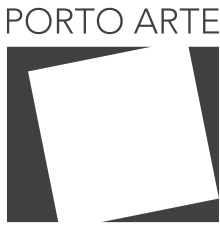

Revista de Artes Visuais v.25 n. 43 Jan/jun 2020 e-ISSN: 2179-8001

Figura 1: A esquerda OPAVIVARÁ, Rede Social (2017 2019), Oito redes unidas e com chocalhos de plástico nas varanda, $400 \times 700 \times 425 \mathrm{~cm}$. A direita: Vista do vão central do CCBB São Paulo-SP. Exposição

Vaivém" (2019-2020), no

Centro Cultural Banco do Brasil-SP. Fonte: Catálogo da exposição "Vaivém". Fotografias Edson Kumasaka

rância na cidade de Belo Horizonte/BH - reuniu 141 artistas, de lugares de fala muito distintos, corroborando para a complexificação da mediação da cultura visual em torno das imagens que associam a tecnologia ameríndia originária da rede ao Brasil e seus contextos discursivos. Tendo em vista que o primeiro espaço a receber a exposição foi o CCBB São Paulo/SP, a espacialização da proposta curatorial respondeu, inicialmente, às especificidades desta edificação, demandando nos demais espaços de exibição as necessárias adaptações. Embora a expografia de Vaivém (2019-2020) se constitua a partir de 6 (seis) núcleos3 temáticos, a exposição não é linear e, tampouco, visa segmentar a arte indígena contemporânea das obras de artistas não-indígenas; ou, ainda, segmentar os artistas europeus de artistas não-europeus, e isso graças à sua nítida atitude trans-histórica4. Vale frisar, ainda, que apesar do projeto curatorial tender ao giro decolonial nas artes, essa exposição não pretende implodir a arte européia nem ignorar, por exemplo, as vozes de artistas indígenas. Mas, sim, alertar para a coexistência de diferentes pontos de vista sobre as redes, convidando o
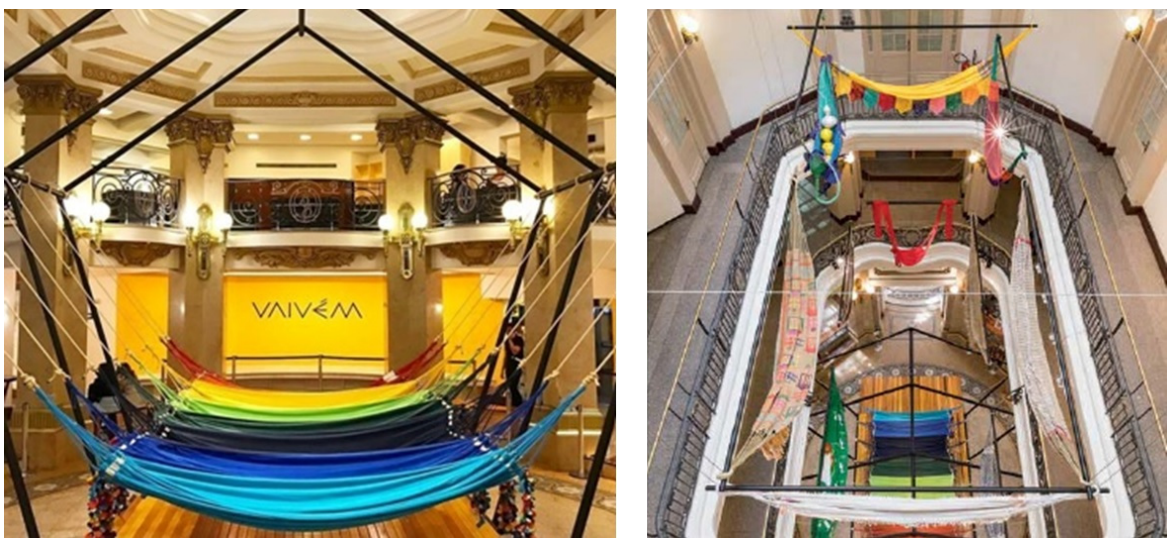

\footnotetext{
3-Resistências e permanências (núcleo que reúne obras de artistas contemporâneos indígenas e não-indigenas, cuja rede é tomada como símbolo e objeto ubíquo da cultura dos povos originários do Brasil); A rede como escultura, a escultura como rede (núcleo que tensiona as redes de dormir a partir da linguagem escultórica); Olhar para o outro, olhar para si (núcleo que intencionalmente coloca lado a lado os documentos e trabalhos de artistas históricos e viajantes, que registraram o cotidiano do Brasil durante a colonização; e trabalhos de artistas contemporâneos indígenas convidados a desconstruírem o olhar eurocêntrico dessas imagens a respeito de seus antepassados, propondo novas narrativas); Disseminações: entre o público e o privado (núcleo que apresenta as redes em atividades cotidianas do Brasil colonial, como mobiliário, meio de transporte e práticas funerárias, bem como os lugares que elas ocupam no Brasil contemporâneo); Modernidades: espaços para a preguiça (núcleo que exibe trabalhos em que a rede é associada à preguiça, à fadiga do corpo e ao descanso, fruto da convergência entre trabalho braçal e calor tropical); e Invenções do Nordeste (núcleo que foram concentradas obras que aludem à mitologia, a respeito da relação entre as redes e esta região do país; além de trabalhos em que as redes emergem como símbolo de orgulho local devido, também, sua importância para a economia da indústria têxtil).

4- A atitude trans-histórica a que me refiro perpassa o regime ético intrínseco ao pensamento histórico defendido por Michel Foucault. No âmbito do projeto foucaltiano de realização de uma história dos sistemas de pensamento. Foucault procurou ultrapassar a ideia de um sistema de pensamento como sendo um episódio na história das ideias para esclarecer processos que instauram novas formas de racionalidade, de técnica, de autonomia e de autoridade do saber. Tal atitude inoculou a abordagem da trans-historicidade como uma saída da história problematizada pelas análises históricas foucaultianas da década de 1970. Assim, a atitude trans-histórica, em Michel Foucault, opera o entrecruzamento metodológico, epistemológico e ético, a fim de instaurar a diferença na história, via descontinuidades, rupturas e reinvenção das determinações no curso do tempo presente. Visa-se, com isso, a construção e a criação de modos inéditos, metamorfoses e experimentações para além do que se encontra posto no interior das determinações históricas
} 


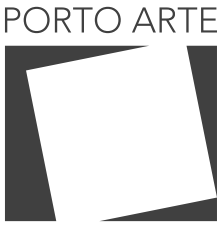

Revista de Artes Visuais v. $25 n .43$ Jan/jun 2020 e-ISSN: $2179-8001$

Figura 2: À esquerda: Aline Baiana, Expropriação (2016), Arame farpado, distanciador de cerca e arame, $140 \times 350 \times 60$ $\mathrm{cm}$. Ao meio: Talles Lopes, Sem título (2019), Instalação $390 \times 300 \times 150 \mathrm{~cm}$. A direita Paulo Nazareth, Trabalho (2007), Instalação/Performance com rede, folha de ponto e trabalhador assalariado Exposição "Vaivém" (2019-2020) no Centro Cultural Banco do

Brasil-SP. Fonte: Catálogo da exposição "Vaivém". Fotografias Edson Kumasaka. público a dissecar essas relações a partir de um complexo processo crítico de montagem-desmontagem-remontagem - de mistura temporal, mas, também, de narrativas e narradores, de tempos e narrações heterogêneas - cujo fluxo pressupõe aproximações, tangências, atritos e contaminações entre diferentes momentos históricos, linguagens e geografias do Brasil.

Operando a compatibilização da equação entre interatividade, responsabilidade institucional e fluxo de visitação, optou-se por dispor no térreo, logo na entrada da exposição, um trabalho mais interativo, a instalação Rede social (2017-2019) (fig. 01), do coletivo de artistas carioca OPAVIVARÁ! - que se tratam de oito redes costuradas, onde o público, aí sim, pode subir, deitar, dormir, descansar, etc. Ocupando o espaço do vão central do prédio, outras redes, com registros muito distintos, feitas tanto por indígenas quanto por associações de artesões do Brasil, ou, ainda, feitas por pessoas que passam pelo circuito da chamada arte contemporânea - permitindo que o público tivesse uma relação mais contemplativa e simbólica com as redes, do que propriamente de repouso do corpo. Nesse sentido, entre as cerca 350 obras que integram a mostra, há três trabalhos (fig. 02) que parecem convidar o público ao deslocamento dessas imagens, apontando para a sua contemporaneidade - a co-presença do próprio presente que elas inevitavelmente perscrutam, quais sejam: Expropriação (2016), de Aline Baiana; Sem título (2019), de Talles Lopes; e Trabalho (2007), de Paulo Nazareth.
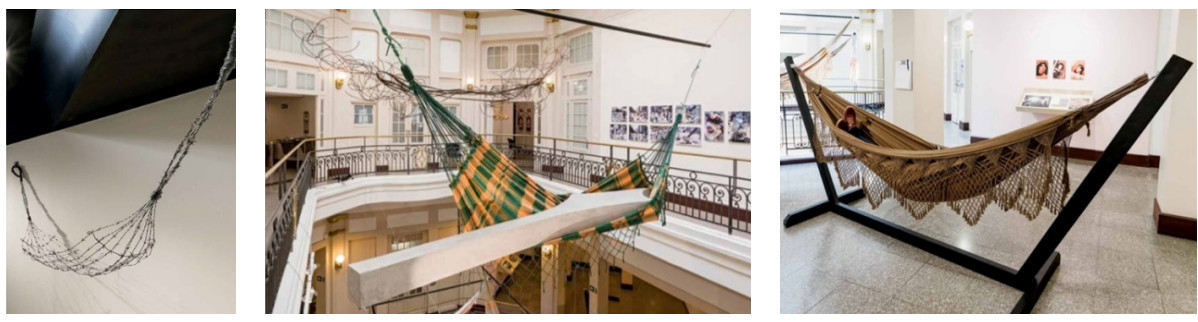

O primeiro deles é a obra Expropriação (2016), da artista baiana Aline Baiana, na qual expõe uma rede de arame farpado. 0 título do trabalho, aliado às origens da própria rede, bem como à fantasmagoria que arrodeia o material escolhido para sua execução, nos leva a pensar no quanto que esse trabalho afere, de forma bastante visceral, a luta pelas terras dos povos indígenas no Brasil, na medida em que se constitui a partir de um elemento que simboliza, delimita e demarca muito concretamente o que é "meu" do que é do "outro", o que é público e o que é privado. É uma rede urdida a partir da linguagem escultórica e que, obviamente, o público não pode se deitar nela. Ao mesmo tempo, trata-se de uma rede que causa uma fascinação nos espectadores que a vêem, por exemplo, como rede que não é para qualquer um estar ali. Ainda sob essa ótica de uma experiência inóspita ou de hostilidade que a obra alude, não há como não se confrontar com esse trabalho e não pensar (a partir do urbano) nas configurações dos mobiliários das cidades na atualidade. Sobretudo porque, de modo cada vez mais recorrente, o modus operandi segregacionista de produção dos espaços urbanos, utiliza-se de estratégias do designer para deter que um corpo qualquer possa se apro- 


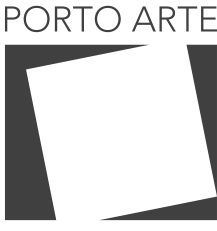

Revista de Artes Visuais

$\vee 25 n .43$

Jan/jun 2020 e-ISSN: 2179-8001

priar das arquiteturas dos espaços urbanos públicos para descansar, especialmente em face da hiperconexão e a superaceleração do cotidiano no contemporâneo.

O segundo trabalho é a obra "Sem título" (2019), do jovem artista goiano Talles Lopes. Trata-se de um trabalho fruto de suas reflexões sobre a coluna do Palácio da Alvorada, em Brasília/DF, e como que essa coluna é replicada na arquitetura popular pelo estado de Goiás. 0 artista expõe uma rede de dormir com as cores da bandeira brasileira como suporte para uma réplica antropomorfizada da coluna do Palácio da Alvorada, como se fosse um corpo deitado, um corpo descansando. Nele podemos vislumbrar mais que uma espécie de metáfora para essa Brasília sonolenta, esse governo em estado de sono, de anestesia. Podemos entrever, também, como que esse elemento excede a monumentalidade de sua função arquitetônica de origem e passa a habitar o cotidiano do imaginário coletivo e onírico do povo brasileiro. Podemos, ainda, presenciar o desequilíbrio e a fadiga das culturas tradicionais em face do peso da incorporação da modernidade industrial. Indo além, se lembramos que essa coluna pode ser vista como uma espécie de alegoria do corpo candango5, dos corpos dos trabalhadores que construíram Brasília, essa obra daria a ver pelo menos dois tipos de corpos obliterados nesse capítulo da história do país: um é o corpo exausto, que nos raros momentos de pausa no regime de quase escravidão que foi construir uma capital em quatro anos, usa a rede para descansar; o outro é o corpo morto, que sucumbiu aos muitos acidentes decorrentes da total falta de seguridade daqueles trabalhadores (o que denota um encargo menos conhecido da rede: o funerário).

O terceiro e último é a obra "Trabalho" (2007), do artista mineiro Paulo Nazareth. Ele se utiliza de elementos, em princípio contraditórios, a saber: a folha de ponto (associada ao trabalho) e a rede (associada ao ócio), para propor uma espécie de instalação/performance cujo ativação do binômio trabalho/cansaço é o que interessa. Aqui, a tensão que a performance suscita não é corporificada pelo artista, mas sim pelo corpo de uma pessoa que, por meio de anúncio em jornal de grande circulação, é contratada para trabalhar na rede em centro cultural, em horário comercial, durante o período de exibição. A controvérsia não é gratuita e parece ter como intenção expor, justamente, a dupla configuração inerente à proposição: seu trabalho como artista e o trabalho da pessoa contratada para estar ali e repousar. Se por um lado, tensiona-se a carga simbólica de repouso creditada à rede (na medida em que ela, a rede, é paradoxalmente apresentada como "ambiente de trabalho"); por outro, Paulo Nazareth põe em relevo, também, a condição límbica que envolve as reconfigurações em torno da ideia de trabalho no contemporâneo, no qual a própria atividade artística, ou mesmo a fruição dela, parece não escapar.

\footnotetext{
5- O termo "candango", aqui, é utilizado em referência à maneira como eram chamados as pessoas que migraram para Brasília /DF para trabalhem como operários na construção da capital federal, em sua grande maioria formada por migrantes do norte e nordeste do Brasil. Esse termo ainda diz respeito ao modo como as pessoas que nasceram em Brasília/DF utilizam para identificar-se com a sua cidade de origem. Contudo, há um terceiro significado para o termo que antecede a esses dois. De origem controversa, segundo o dicionário Priberam, "candago" tratava-se do modo como parte dos africanos escravizados se referiam aos portugueses, cujo significado para aqueles pode ser equivalente a indivíduo desprezível, abjeto.
} 


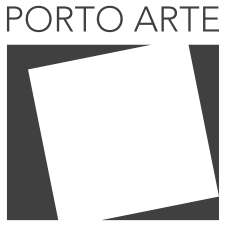

Revista de Artes Visuais

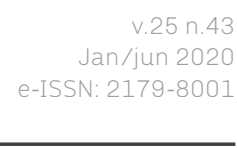

Figura 3: João Luiz Guimarães, Sem título (2019), Fotografia Fotografia que ilustra a matéria "Acima dos muros", de Eliane Brum, para o portal El País Fonte: El País. Fotografia João Luiz Guimarães

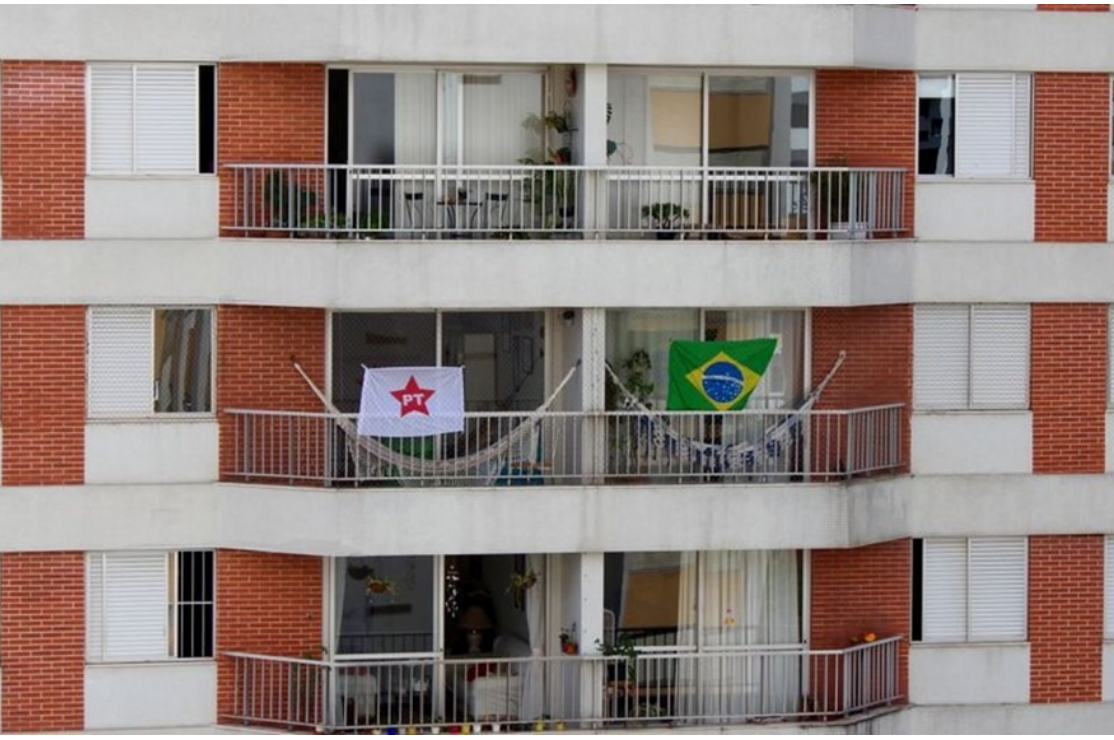

Caminhando para o encerramento, recupero, aqui, uma imagem apresentada por Raphael Fonseca durante a conferência "Entre o cansaço e a preguiça: sobre corpos que tombam"6 (2019b). Trata-se de uma fotografia (fig. 03) de João Luiz Guimarães que ilustrou a matéria "Acima dos muros", escrita por Eliane Brum e publicada no Portal do El País, em 28 de março de 2016, cuja pauta discorria sobre um Brasil polarizado às vésperas do impeachment da ex-presidente Dilma Rousseff. Embora a imagem não integre a mostra Vaivém (2019-2020), ela, no entanto, se constitui tanto para o curador quanto pra nós como um importante dispositivo analítico para se pensar a atualidade e pertinência da exposição.

$\mathrm{Na}$ imagem temos duas varandas de um prédio em São Paulo-SP, em que num segundo plano, a rede se faz presente. Entretanto, num primeiro plano, enquanto na varanda à esquerda figura a bandeira do Partido dos Trabalhadores; a varanda à direita, por sua vez, figura a bandeira do Brasil. Se considerarmos o contexto histórico que circunscreve a imagem, bem como a carga simbólica que pesa o imaginário sobre os elementos que a compõem, a saber, as bandeiras e a rede - analisando-a apenas sob a ótica do discurso estereotipado sobre o outro, disseminado à época (e ainda hoje) - pode-se dizer que, por um lado, a rede à esquerda seria uma rede que acolheria um corpo vadio, que se beneficia das ações afirmativas e que, na visão da ultradireita, só reforçariam o "coitadismo" no país; enquanto, por outro lado, a rede à direita tratar-se-ia de uma rede que acolheria aquele corpo, visto pela ultraesquerda, como a reencarnação do senhor de engenho, o grande empresário, corpo historicamente favorecido e que não vê, por exemplo, o descanso como algo de todos e, sim, de poucos privilegiados. Sem pender para nenhum dos lados, o que interessa, aqui, é demonstrar o quanto que

\footnotetext{
6- A conferência "Entre o cansaço e a preguiça: sobre corpos que tombam", do curador Raphael Fonseca, foi realizada no dia 27 de setembro de 2019, no auditório do Cemuni IV - Centro de Artes, da Universidade Federal do Espírito Santo (UFES), como parte da programação da exposição "Ao Redor do Sono", em cartaz na Galeria de Arte e Pesquisa, UFES, de 27 de agosto a 04 de outubro de 2019.
} 


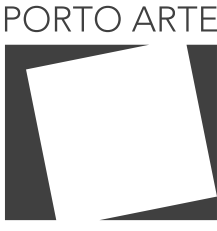

Revista de Artes Visuais

$\vee 25 n .43$

Jan/jun 2020 e-ISSN: 2179-8001

a capacidade de apreender as nuances de uma dada imagem pode ser rapidamente manipulada em favor da reificação de certos clichês - no caso dessa imagem não somente sobre a rede, mas também, sobre a política, sobre os corpos, sobre o Brasil e, também, sobre uma suposta noção de uma identidade brasileira.

Não restam dúvidas de que o projeto curatorial da mostra Vaivém (2019-2020) caminha no sentido oposto. Atrevo-me a dizer que a atitude de Raphael Fonseca implica em uma tentativa, a meu ver, extremamente bem sucedida, não só de tensionar a imagem como campo de explorações e descobertas - que recusa qualquer síntese conclusiva final, tão cara aos estereótipos e ao senso comum - como convida o próprio público à participação ativa e colaborativa neste processo. Uma forma de conhecimento a partir da imagem próxima ao que Deleuze \& Guattari (1997) chamaram de "ciência nômade", "excêntrica" ou "menor". Com essa atitude, o curador nos lembra que, em última instância, ante a disseminação acrítica de imagens e discursos que endossam os estigmas nacionais em torno da cultura brasileira, cabe a nós seguirmos engajados na construção de análises que estranhem e perscrutem esses lugares-comuns, pois "[...] sem essa ação, não somos capazes de escrever novas narrativas identitárias para o futuro" (FONSECA, 2019a, p.11).

\section{DADOS DA EXPOSIÇÃO:}

\section{Exposição Vaivém, com curadoria de Raphael Fonseca}

Em cartaz nos Centros Culturais Banco do Brasil de São Paulo/SP (de maio a julho de 2019), de Brasília/DF (de setembro a novembro de 2019), do Rio de Janeiro/RJ (de novembro de 2019 a fevereiro de 2020), e de Belo Horizonte/BH (de março a maio de 2020).

\section{REFERÊNCIAS}

DELEUZE, Gilles e GUATTARI, Félix. Mil Platôs. Capitalismo e Esquizofrenia. Vol. 5. Rio de Janeiro: Editora 34, 1997.

FONSECA, Raphael. Construções do Brasil no vaivém da rede de dormir. 2016. $468 \mathrm{f}$ Tese (Doutorado em História da Arte) - Programa de Pós-Graduação em Artes, Instituto de Artes, Universidade Estadual do Rio de Janeiro, 2016.

FONSECA, Raphael. 5 perguntas a Raphael Fonseca. [Entrevista cedida a] Gabriela Name, Gabriela Mureb e Zé Carlos Garcia. In: Site Daniela Mane: algumas palavras sobre cultura, Rio de Janeiro, 16 de mai. 2016. Disponível em: <https:// daniname.wordpress.com/2016/05/16/5-perguntas-para-raphael-fonseca/>. Acesso em 06 jan. 2020.

FONSECA, Raphael. Introdução. In: FONSECA, Raphael (org.). Catálogo da exposição Vaivém. São Paulo: Conceito, 2019a.

FONSECA, Raphael. Entre o cansaço e a preguiça: sobre corpos que tombam. [Conferência proferida em 27/09/2019]. In: Exposição coletiva "Ao Redor do Sono". Vitória: GAP/UFES, 2019b. 


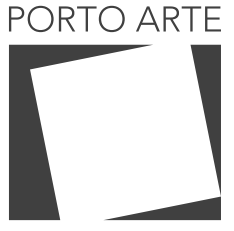

Revista de Artes Visuais

V.25 n. 43

Jan/jun 2020 e-ISSN: 2179-8001

Texto recebido em: $27 / 04 / 2020$

Texto aceito em 15/06/2020 Texto publicado em 30/06/2020

\section{Lindomberto Ferreira Alves}

Artista-educador, pesquisador, crítico e curador independente. Mestre em Teoria e História da Arte pelo PPGA-UFES (2020). Licenciando em Artes Visuais pela UNAR/SP (2020) e Bacharel em Arquitetura e Urbanismo pela UFBA (2013). É membro do grupo de pesquisa "Curadoria e Arte Contemporânea"; e integra a equipe da "Plataforma de Curadoria" (DAV-UFES), plataforma virtual focada nos processos de criação em curadoria. Possui textos publicados em livros, catálogos e revistas especializados nos campos da história, teoria e crítica de arte. Suas investigações privilegiam a análise dos processos de criação na arte contemporânea, de modo especial, no estudo de produções cujos processos criativos colocam arte, vida e obra no mesmo plano de contágio. 